\title{
Can one retell a Mozambican reform story through Problem Driven Iterative Adaptation?
}

\author{
Matt Andrews \\ CID Working Paper No. 278 \\ February 2014
} (C) Copyright 2014 Andrews, Matt and the President and Fellows
of Harvard College

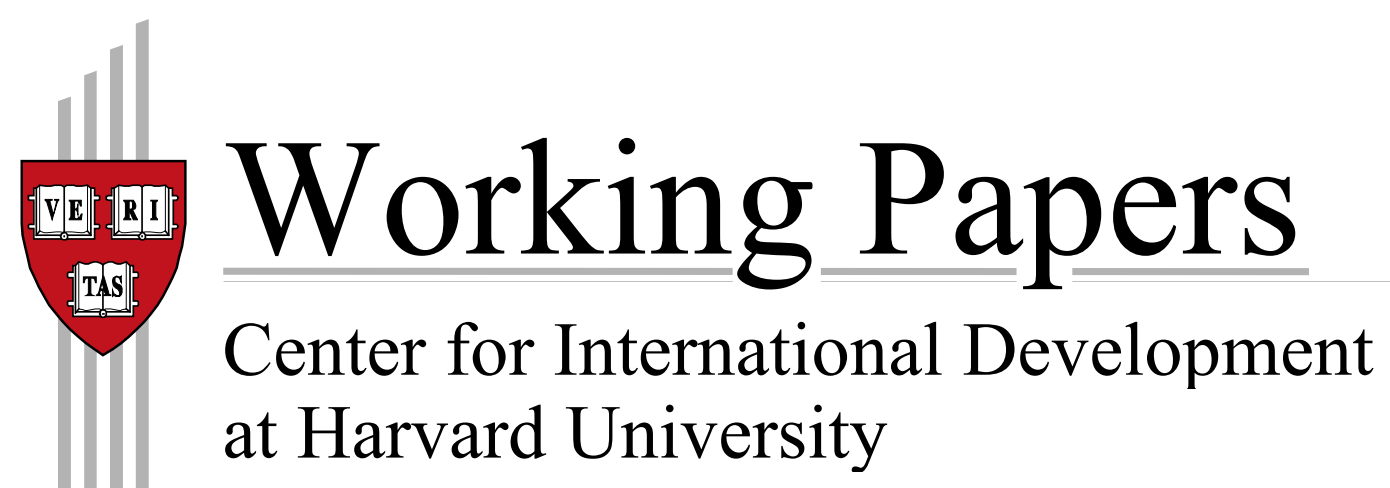




\title{
Can one retell a Mozambican reform story through Problem Driven Iterative Adaptation?
}

\author{
Matt Andrews
}

February 2014

\begin{abstract}
Many public sector reforms in developing countries fail to make governments more functional. This is typically because reforms introduce new solutions that do not fit the contexts in which they are being placed. This situation reflects what has recently been called the 'capability trap' in development-which results in many interventions producing new forms that are not functional in states across the globe. The work on capability traps suggests that reforms can yield more functional influence in even the most complex states, however; if reformers adopt non-traditional approaches to doing reform. In particular, the work suggests that reforms will tend to be more contextually fitted if: (i) They are driven by problems that agents in the context care about; and (ii) They are introduced iteratively-through a stepwise process where ideas are tried and lessons are learned and used to adapt (or fit) ideas to context. The capability traps work embeds these ideas into an approach to doing reform called Problem Driven Iterative Adaptation (PDIA). This approach has deep roots in various literatures but many observers still ask how PDIA-type reforms could work to foster successful reform in complex hierarchical developing country governments and whether these approaches really help foster reforms that better fit such complex contexts. This paper responds to such question by describing an action research study where PDIA is being used to retell a story of reform that has to date been limited. The action research study is in Mozambique's judicial sector and will examine whether and how a problem driven iterative approach can (i) flush out the contextual factors that often limit reform success, (ii) provide a viable route to find and fit reforms that actually foster greater functionality, and (iii) promote the authority needed to ensure change is implemented and institutionalized.
\end{abstract}




\section{Introduction}

Many public sector reforms in developing countries fail to make governments more functional. This is typically because reforms introduce new solutions that do not fit the contexts in which they are being placed. Project processes that structure such reforms commonly fail to allow reformers to see or respond to contextual factors that ultimately undermine reform success (like political resistance or capacity constraints that are hidden from sight or underestimated when projects are prepared). As a result, such projects either fail outright or produce new forms - like laws or management systems-that are not used or useful. The problems that initially warranted reform remain unsolved and the governments involved are no more functional or capable than they were before reform.

This situation reflects what has recently been called the 'capability trap' in development-which results in many interventions producing new forms that are not functional in states across the globe (Andrews 2013; Andrews, Pritchett and Woolcock 2013; Pritchett, Woolcock and Andrews 2013). The work on capability traps suggests that reforms can yield more functional influence in even the most complex states, however; if reformers adopt non-traditional approaches to doing reform. In particular, the work suggests that reforms will tend to be more contextually fitted if: (i) They are driven by problems that agents in the context care about; and (ii) They are introduced iteratively-through a stepwise process where ideas are tried and lessons are learned and used to adapt (or fit) ideas to context. Iteration is promoted as a means to flush out contextual factors (like political influences and capacity constraints) and to allow the emergence of solutions within the context, given contextual realities; and to progressively grow the authority needed to adopt and implement and institutionalize these solutions.

The capability traps work embeds these ideas into an approach to doing reform called problem driven iterative adaptation (pdia). This approach has deep roots in various literatures (explicitly reflecting the learning process methods proposed in the 1980s) ${ }^{1}$ and is introduced on the basis of extensive empirical evidence that shows successful reforms emerge through such processes. ${ }^{2}$ Regardless of this rich heritage, many observers still ask how pdia-type reforms could work to foster successful reform in complex hierarchical developing country governments and whether these approaches really help foster reforms that better fit such complex contexts. This paper responds to such question by describing an action research study where pdia is being used to retell a story of reform that has to date been limited.

The action research study is in Mozambique and is slated to examine whether and how a problem driven iterative approach can (i) flush out the contextual factors that often limit reform success, (ii) provide a viable route to find and fit reforms that actually foster greater functionality, and (iii) promote the authority needed to ensure change is implemented and institutionalized. The work involved two local coaches and one international academic working with a group of government officials under the auspices of the Minister of Justice to find and fit solutions to data access problems that undermined management in the judicial sector. This intervention was chosen partly because prior multimillion dollar projects focused on addressing the same problem had either failed or stalled, ostensibly because of

\footnotetext{
${ }^{1}$ See, for example, Bond and Hulme (1999), Chambers (1997), Korten (1980), Rondinelli (1993), Uphoff (1985), Uphoff, Esman, and Krishna (1998).

${ }^{2}$ See Andrews (2013a, 2013b).
} 
contextual constraints that the reform designers did not foresee. These past projects provided a counterfactual against which to compare the pdia-type approach.

This paper starts by discussing the past projects tackling data access in Mozambique's judicial sector. It shows how these projects achieved limited success and argues that this is because the solutions they introduced were poorly fitted to the Mozambican context. It suggests that this is an 'old and oftrepeated' story in development but then argues that there is another way-pdia. A second section suggests that this new approach could help reformers re-write reform stories in places like Mozambique. It offers a practical and theoretical explanation of this approach. The third section then describes the action research method adopted to test key hypotheses implied in pdia. The conclusion notes that the action research study is still in process and this prohibits any formal and final findings. These findings-and the action research story itself-will be discussed in detail in future work.

\section{A brief story of reform in Mozambique's justice sector}

Mozambique emerged from a messy civil war in the early 1990s. Since that time its government has been very active in introducing reforms. Many of these reforms have been in the governance realm, with the justice sector targeted for a number of interventions. Judicial access was the dominant focus of reforms in this sector in the late 1990s and early 2000s, and data show that the number of citizens seeking justice grew significantly in this period. ${ }^{3}$ As often happens, the success in expanding access generated a new set of challenges. Chief among these were the many management gaps the judicial sector faced when trying to deal with the growing demand for justice. About 100,000 new cases were entering the judicial process each year by 2005 . The sector was settling fewer than 90,000 cases each year at the time, however, and had a backlog of over 200,000 cases. This meant that backlogs were growing, the time to settle cases was widening, and trust and confidence in the judicial process was under threat.

The challenge of managing this growing caseload was made more complicated by the new kinds of laws and courts that had been created in Mozambique. New types of legal offerings had to be addressed in the courts (including commercial law cases and labor law cases) and new administrative and judicial bodies were emerging or being re-shaped. Further complicating the situation were commonly found tensions that existed between bodies in the sector-the Ministry of Justice, Courts, Prosecutor General's Office, and more. These bodies struggled to coordinate in ways necessary to manage the new service demand. This poor coordination manifest in weak data and information access across the sector. Sector leaders claimed that data existed to accurately show where the sector faced its biggest demand challenges and how resources were being structured in response to such demand. However, there was no single place where one could find reliable data on basic things like case loads, presence of judges, presence of prosecutors, budgetary allocations, building access, or the like. This meant that management decisions that demanded some basis in evidence were made without such evidence. An example of this problem is evident in a 2008 review of an African Development Bank loan that could not

\footnotetext{
${ }^{3}$ The background commentary on Mozambique draws on various sources including Mussanhane (2008), Open Society Foundation (2006), UNDP (2007), and European Commission (2009). Data was analyzed by the author and comes from officials in the Ministry of Justice.
} 
assess a key performance metric that focused on the number of cases cleared per judge. Some caseload data existed in the sector but this could not be related to accurate data on where judges were located. ${ }^{4}$

The sector's coordination issues had been a focal issue since the early 2000s, when a Council for Coordination of Law and Justice (CCL) was created. This council made some inroads in fostering formal cooperation in the sector and led to the writing of a Justice Sector Strategic Development Plan, covering the period between 2007 and 2012. A centerpiece of this strategy was the planned Integrated System for Justice Sector Planning, Monitoring and Evaluation (SIPMAJ). First announced in 2007, SIPMAJ was intended to provide an information technology (IT) system that would house "a joint information database, gathering different sets of data relevant to the Justice sector" and facilitating more evidencebased management across the entire sector (UNDP 2007, 20)..

SIPMAJ was introduced as part of a series of externally funded projects supported by a variety of donors. According to official estimates, the projects disbursed between 5 and 7 million dollars to a team of IT consultants charged with creating SIPMAJ. By 2012, however, there was no system in place in the justice sector. There are no evaluations of the project and no formal assessments exist to explain what happened to SIPMAJ or why it has not delivered the improved functionality it was meant to. Some officials in the justice sector refer to it as the 'Maputo Myth'. Other officials note that the project has actually produced a complete software solution for the justice sector but this solution has not been activated because of contextual complexities and constraints. These officials note that donor financing was not sufficient to support actual implementation of the new software. They note that domestic financing was also not available; ostensibly because the project never enjoyed enough local political or bureaucratic support. Political and bureaucratic leaders had committed verbally to support coordination, but this verbal commitment had never been translated into actual engagement in the SIPMAJ initiative or into financial support for such. The entire exercise was channeled through a narrow project implementation unit and involved eternal consultants working at an arms-length distance from actors in the justice sector who would ultimately need to provide data in the SIPMAJ system, use the system to analyze the data, and implement and institutionalize the system in everyday work.

The result was that the justice sector still had no comprehensive source of data to use in managing resources and making decisions in 2012-more than five years after the SIPMAJ initiative was announced and over $\$ 5$ million worth of support had been spent.

\section{An old and oft-repeated story}

The SIPMAJ story is not peculiar to Mozambique or to the area of judicial reform. A large number of reforms enter systems through expensive and (ostensibly) well-intended projects but ultimately achieve limited (or no) functional results. This is a core message of the new literature on capability traps, which emerged from empirical observations of many reforms that fail to improve government functionality (Andrews 2013; Andrews, Pritchett and Woolcock 2013; Pritchett, Woolcock and Andrews 2013). This literature notes that such failure is often repeated again and again in the same countries, with the same reforms, suggesting that many governments are caught in a 'trap' when it comes to institutional change.

\footnotetext{
${ }^{4}$ See the Project Completion Report for the Poverty Reduction Support Loan PRSL I), August 2008.
} 
The trap exists because reform challenges facing states are commonly complex in nature, but traditional development and project processes are not well suited to address such complexity.

The complexity emerges largely because areas like judicial management involve many different agents operating in different authorizing structures, with high levels of interdependent and opaque relationships (both political and bureaucratic), and limited revealed capacity. Although it is unclear what kind of solution is really needed or will be viable to solve the festering problems in such complex settings, traditional project mechanisms like that used to introduce SIPMAJ require the identification of a 'solution' before funding is provided. This means that would-be reformers in areas like Mozambique's judicial sector need to agree ex ante to a solution that appears impressive enough to garner external support. Ideally, one would hope to gain added state functionality from such reform solution as well (moving directly from A to B in Figure 1, which shows the dual challenge of legitimacy and functionality in reform). Contextual complexities often make it impossible to know ex ante how to achieve this improved functionality, however (hence the tentative diagonal arrow from A to B).

Figure 1. The dual challenge of legitimacy and functionality in reform

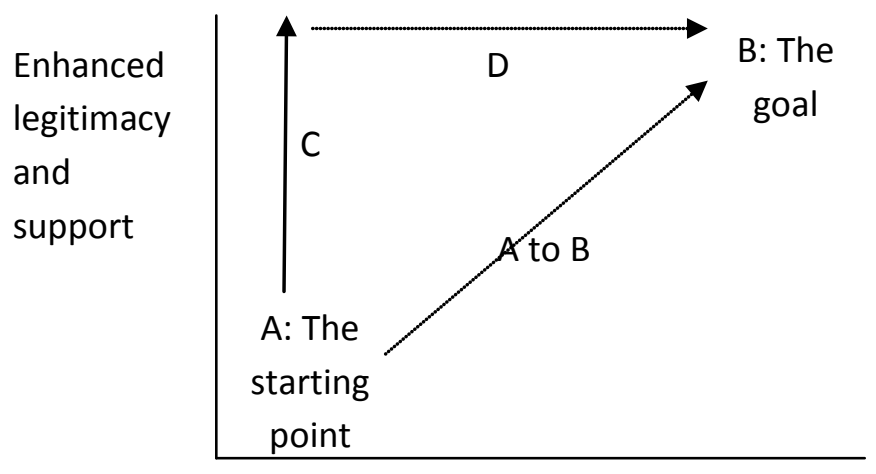

Enhanced functionality

Source: Author's original analysis

Faced with such a situation, reform designs often focus on producing solutions that are legitimate enough to obtain external funding (shown in the vertical arrow $\mathrm{C}$ ) with the hope and assumption that these solutions will ultimately also yield improved functionality (as implied in the tentative arrow D). These kinds of 'solutions' are often impressive looking, and commonly reflect what outside agencies would define as a 'good' or 'best' practice (like SIPMAJ; an impressive, integrated sector-wide IT system that absorbs significant funding and appears to be a serious solution). This kind of reform design works in the short run for donors (who can claim that government officials have committed to do an impressive reform) and government officials (who can claim resources and other support from the donors, and a potential solution to pressing problems). In the medium to long run, however, the reforms commonly do not yield greater functionality because assumptions underlying the ' $D$ ' arrow prove problematic. Contextual complexities-from political tensions to capacity constraints, changes in 
bureaucratic leadership, financial shortfalls, and the like-limit the implementation, use and usefulness of the new solutions.

This is much like the story officials tell when explaining what happened to SIPMAJ: The initiative looked impressive enough to garner external support but local support was not sufficient to facilitate implementation of the new software and sector wide political and bureaucratic authorization was never enough to ensure that the initiative engaged end users in the judicial sector. The SIPMAJ story should not be read as a negative reflection on the Mozambican authorities involved in the reform, however. This kind of experience is commonly seen in development more broadly: new anticorruption laws are frequently adopted to much fanfare, but never get implemented; public financial management systems exist technically but are not used in many countries; and more. The story is also common in the area of IT-based reform in private organizations, where estimates suggest that over $80 \%$ of reforms produce new systems (like SIPMAJ) that are not used or do not work effectively in their prospective contexts. ${ }^{5}$

\section{A new approach might yield a new-and more successful--story}

The capability traps literature argues that reform stories do not need to end with this kind of failure. Interventions in complex contexts (and dealing with complex problems) can have more impact; if they are introduced through a different reform approach. In particular, the work suggests that reforms will tend to be more contextually fitted and have more functional impact if: (i) They are driven by problems that agents in the context care about; and (ii) They are introduced iteratively-through a stepwise process where ideas are tried and lessons are learned and used to adapt (or fit) ideas to context.

The capability traps work embeds these proposals into an approach to doing reform called problem driven iterative adaptation (pdia) (Andrews 2013; Andrews, Pritchett and Woolcock 2013). This approach has deep roots in various literatures. It draws explicitly on the learning process methods proposed for international development in the 1980 s. ${ }^{6}$ It also builds on work by authors like Hirschmann (1967) and Lindblom (1959) and change management theories and practices like Deming and Shewhart's work on plan-do-check-adapt (PDCA) strategies (Deming 1986; Shewhart 1980). Additionally, pdia's fundamental principles and proposed practices align with approaches adopted recently in the information technology world-most notably the agile methodology used to define software solutions for complex organizations.

\footnotetext{
${ }^{5}$ For instance, a 2002 study found that only $2 \%$ of the software developed out of $\$ 35.7$ billion of IT spending in the United States' Department of Defense was usable or delivered. Three quarters of the software that was developed was in fact never delivered or as never used. Further evidence comes from Harvard Business School academics Robert Austin and Richard Nolan, who found that many large scale IT projects fail because of flawed assumptions in design. They identify these 'flawed assumptions' in a way that draws parallels with the agument in this paper: "The first flawed assumption is that it is possible to plan such a large project. The second flawed assumption is that it is possible to protect against late changes. The third flawed assumption is that it even makes sense to lock in big projects early."

${ }^{6}$ See, for example, Bond and Hulme (1999), Chambers (1997), Korten (1980), Rondinelli (1993), Uphoff (1985), Uphoff, Esman, and Krishna (1998).
} 
Figure 2 shows how the proposed pdia process works, through a series of six stage 'find and fit' iterations that are intended to foster the gradual but progressive identification and implementation of reforms that help governments escape the capability trap.

1. The first stage of each iteration starts with agents within the change context identifying problems that they care about and need to see addressed. ${ }^{7}$ A group will commonly be engaged in this step when working on institutional reform. This is because the paradox of embeddedness assures that most agents who identify problems will not enjoy the authority to address such problems, and most agents with authority to address problems will not acknowledge that problems exist (Garud and Karnøe 2003; Greenwood and Suddaby 2006; Seo and Creed 2002). Institutional entrepreneurship thus happens through groups (Andrews, McConnell and Wescott 2010; Dorado 2005). Once identified, the problem then allows the group to determine a vision for its change-defined in measures that show what the problem will look like when solvedand to build a change management strategy (breaking the problem down according to causal factors and focusing on entry points to start the change process, for instance).

Figure 2. A six stage 'find and fit' iteration, within the pdia approach

3. Action is taken; members of the group are encouraged to take action and held

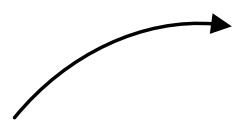

2. Initial action steps are identified by the group (what can we do first/next to start solving the problem?)

1. Locally felt problem is constructed, with clear idea of what 'problem solved' will look like: An entry point for action is identified; a group of local agents is gathered to work on this problem

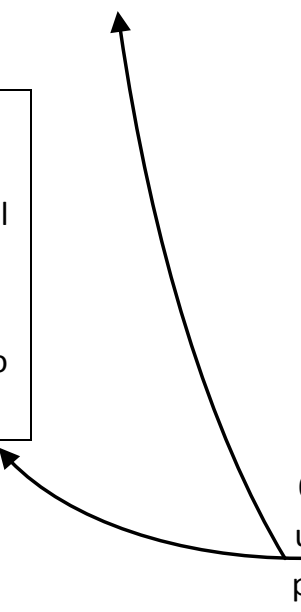

6.ii. If no, build on expanded authority, use lessons to adapt thinking about the problem and potential solution designs,

and iterate again
4. The group takes stock of experience; what results were achieved? What lessons were learned? What challenges were encountered? How did we overcome the challenges?

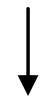

5. Using evidence from the stock-take, group communicates quick wins and lessons to bolster legitimacy and authority, expand support

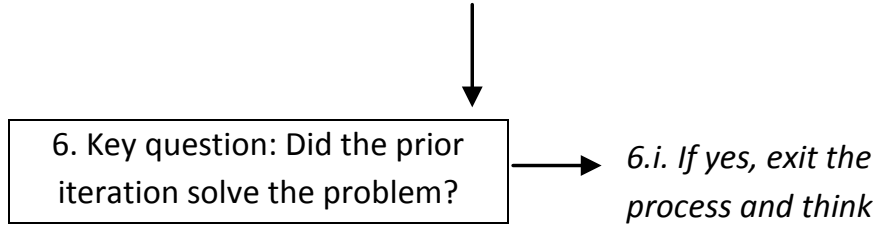
about diffusion or scaling challenge

Source: Author's original analysis

\footnotetext{
${ }^{7}$ Problems are considered key entry points or change (Vis and van Kersbergen 2007).
} 
2. Once the problem has been clarified and entry points for action have been agreed, the group works to identify initial actions it could take to start solving the problem. The scale and scope of these actions depends on various factors, but will probably be more modest in the first iterations and in situations where contexts and problems are very complex and revealed capacity to act is limited. A purposive approach should be taken to choosing these actions, involving a variety of strategies that ensure a broad set of ideas are considered. Specific strategies could include those used in design thinking, rapid results and positive deviance interventions, and in best practice and situational analysis. The goal is to identify actions that allow the group to start actively addressing the problem-working with 'what they have at hand' so as to provoke rapid engagement with the context.

3. The groups then progress into a third action stage. Members work individually and in combinations to complete the actions identified in stage 2 . They are enabled by outside coaches in this process, who encourage their action and also ensure they are all held accountable to complete the activities for which they are responsible. This action stage is vital because reform ideas are pushed into the context through real engagement. Lessons will be learned about contextual constraints that may be unseen in more passive reform design phases, and new opportunities may arise through real interaction as well. Most importantly, the reform groups build actual capabilities needed to make successful reforms-or learn by experience which capabilities they lack.

4. A specific stage is needed to take stock of the progress made and lessons learned in the action stage. Outside coaches are often needed to broker discussions in this stage because they have some distance from the action and can help reformers see into their individual experiences and make sense of experiences across the group. These coaches will gather information about what was done, what was learned, what obstacles were encountered, and what was done to overcome these obstacles. Appreciative inquiry methods are useful in this stage, fostering an awareness of progress which, no matter how small, can both inspire and inform reform groups. Similarly, lessons from experience can help reform groups adapt ideas to contextual constraints and opportunities and promote the chances of finding and fitting a truly functional solution.

5. Information emanating from this learning stage is not just useful for helping the reform group learn about achieving functional change. It is also a resource to use in managing political concerns and expectations associated with the change process. Change processes always need to be authorized, and the requisite authority often grows as a change process progresses. The authorizing environment is constantly shifting as well, given expected and unexpected political and bureaucratic transitions and other factors. This means that the reform process must embed intentional initiatives to consistently consolidate and build authority. This is done in stage 5 , where reform groups communicate quick wins and lessons learned, bolstering the legitimacy of the reform process and ensuring support for continued reform. 
6. Stage 6 of each iteration should see the groups revisiting the rationale for change, asking if their actions actually solved the problem driving reform. If the answer is 'yes', given metrics the team agrees to use in assessing if the problem is solved, then the group activity needs to exit the iterative process and move towards a new strategy of diffusing or scaling the solution they have 'found'. (This new strategy could involve a more traditional blueprint based project approach, given that a viable solution has now been found and theorized). If the answer is 'no', however, the groups will prepare to enter a new iteration: building on expanded authority, using new lessons to adapt thinking about the problem and potential solution designs, and determining new action experiments to pursue. The number of iterations one can expect in any reform experience will depend on various factors, but will probably be higher in situations where contexts and problems are very complex and revealed capacity to act is limited.

The 'find and fit' iteration and pdia process differs significantly from traditional blueprint project mechanisms used to introduce reforms like Mozambique's SIPMAJ. Reformers using pdia are not required to define an impressive looking solution ex ante and then hope and assume that it will be viable in the context and lead to greater functionality. This is good news for coutries like Mozambique, where such assumptions are overly-heroic given the complexity of the context, opacity of the politics, and weak capacity. One should reasonably expect that any new solution will encounter considerable unforseen challenges in such contexts and that these challenges will require considerable adaptation to the proposed solution. This adaptation ensures that the reform enjoys growing legitimacy (given an intentional focus on maintaining and building authority) and ultimately offers the best chance to find and fit a solution that actually improves functionality.

Figure 3 illustrates how pdia achieves this kind of gradual functional improvement wth growing legitimacy. Step 1.1 captures stages 1 to 3 in the discussion above, where reform groups identify and implement actions they have identified as important in solving a particular problem. This step helps the group learn about enhancing state capability and functionality.

Figure 3. Iterating to meet dual challenge of legitimacy and functionality in reform

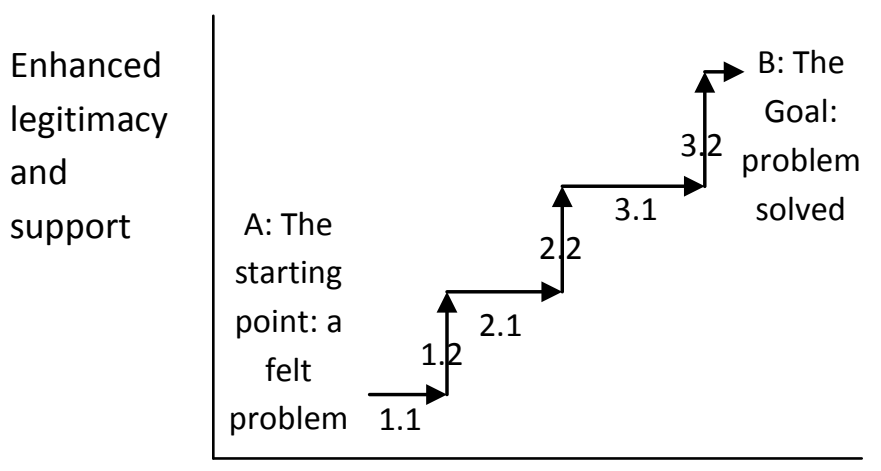

Enhanced functionality 
Source: Author's original analysis

Step 1.2 consolidates stages 4 and 5, where reform groups use information from the earlier stages to consolidate and build legitimacy and support for the reform. At this point, the reform group has not identified a final solution but has progressed somewhat in this direction. It has learned what is needed to fit those parts of the solution that have been identified to the context and it has ensured that there is support for the step that has been taken-and authority to take another step (2.1). As the group iterates through these stages in repeated iterations (steps 2 and 3), it finds and fits more dimensions of the solution to the context. Gradually, this leads to an end point where the problem is solved.

\section{Does this new process really make the difference? An action research study design for Mozambique}

This discussion offers a practical argument in favor of pdia as an improved approach to doing reform in developing countries like Mozambique. The practical argument yields important theoretical hypotheses, however. These suggest that pdia will foster contextually fitted reform solutions that many formal blueprint project processes fail to produce. Three central hypotheses follow:

H1. Pdia-type reforms will facilitate a gradual but progressive identification and response to contextual factors that are commonly unseen in reform designs and undermine reform success.

H2. Pdia-type reforms will facilitate a gradual but progressive emergence of new capabilities that lead towards an ultimate functional solution that fits contextual realities in the reform setting.

H3. Pdia-type reforms will facilitate the maintenance and progressive expansion of reform legitimacy and support, such that next steps in change processes are continually authorized.

Prior work uses retrospective analysis to show that evidence from past reforms supports these hypotheses (Andrews 2013b, 2013b). The evidence shows that pdia principles have been adopted in many successful reforms without those reformers explicitly using a process called pdia. It does not necessarily support the perspective that an intentional problem driven, iterative process will have such impacts, however, or is in fact possible in hierarchical bureaucracies that operate according to rigid project-type processes that may prohibit problem driven iteration. Evidence in favor of this kind of argument requires research that experiments with the explicit use of pdia-type reform strategies in complex, hierarchical developing country contexts.

Action research is arguably the most appropriate method for such work. This method is commonly used in management and development studies focused on analyzing change processes in real world settings where work "aims to contribute both to the practical concerns of people in an immediate problematic situation and to further the goals of social science simultaneously" (Gilmore, Krantz, and Ramirez 1986, 161). The Mozambican judicial data management case provided an ideal opportunity for such work. This opportunity arose gradually from events in $\mathbf{2 0 1 0}$ when the lead author was working informally with staff members in the World Bank's Maputo office. These World Bank specialists were interested in fostering deep problem-driven dialogue with government counterparts and wanted to include the justice sector in this initiative. The Minister of Justice and her senior advisor agreed to participate and brokered a series of multi-stakeholder meetings to discuss the major problems that needed attention across the sector. These meetings repeatedly pointed towards the festering problem of managing a sector with 
weak and fragmented data. As the group discussions deepened, the problem was defined more clearly and an informal idea of 'problem solved' was defined: having sufficient data to make evidence-based budget requests and resource allocation decisions (including decisions about infrastructure projects).

In late 2011 the World Bank team started pushing ministry officials to agree to a 'solution' or 'result' that they could include in a proposed new project. World Bank specialists suggested focusing on producing a new sector wide database and IT system, much like the one SIPMAJ was meant to provide. This proposal was considered impressive enough to warrant support from the World Bank operation but was made with little to no consideration of the SIPMAJ project experience (which was already showing that such an idea was difficult to fit into the Mozambican context). The proposal is what one would expect given core arguments in the capability traps literature, however; it gave the World Bank team a legitimate-looking 'result' for their project and it gave Ministry of Justice officials a way into the project.

Unfortunately, Ministry of Justice officials heard that they were not going to be included in the operation in early 2013; after over a year of intermittent engagement and work to draft project preparation materials. These officials were concerned about next steps, given that they had spent over a year brokering inter-sectoral dialog and now had to deal with the sting of rejection and growing awareness that SIPMAJ was not emerging as a functional solution to the sector's data management problems. Key authorizers like the Minister of Justice were still committed to addressing these problems but did not have any external donors lined up to offer assistance.

Given such situation, the Minister and her senior advisors agreed in February 2013 to try a new pdiatype reform approach. It was agreed that this approach would be problem driven and involve a group of government officials from across the sector working together to gradually build capabilities and find and fit solutions. The only external assistance would come from facilitators working alongside the reform group. One of these facilitators was the author of this paper (an academic from the United States) whose main role was to frame the process and offer technical support when necessary. Two other facilitators were local private sector management specialists hired as coaches. They were responsible for helping the group engage and gathering and recording feedback from group members.

The outside facilitation was sponsored by the United Nations University (UNU-WIDER). It was scheduled to run from April to December 2013 and was intended to involve two or three 'find and fit' iterations (similar to that shown in Figure 1). The structure of each iteration was not as formally defined as it is now (in Figure 1) but the general approach was to follow a particular order of facilitated engagement like those commonly used in action research engagements (Susman 1983; Maclsaac 1995). This would start with a group meeting at which the problem would be agreed and ideas for action would be determined. A basic form of situational analysis was chosen for this process. This would see group members consider the problem at hand and the situation they faced (their resources, time, capacities and so forth), identify lists of potential steps that they could take to address the problem, and prioritize which steps they could adopt in immediate action. Group members would then commit to the action agenda and to particular responsibilities in this. They would agree to a deadline for completing the action and a next meeting date where results and lessons would be discussed. External facilitators would assist in all meetings and would follow up routinely with all group members once they parted to 
pursue the action agenda. The coaches would use appreciative inquiry techniques when following up with group members, asking four key questions: What did you do? What did you learn? What problems did you encounter? What help do you need (and have you asked anyone for help)? This follow up was intended to provide the basis for feedback and experiential learning in future group meetings and would also be used to report back to those authorizing the work. The report back would occur at the end of each iteration, and would be a key point at which next iterations would be discussed and agreed upon.

The exercise involved a new and aggressive approach to doing real world reform, but it also provided an opportunity for academic learning about the potential value of pdia-type engagement. This opportunity was extremely valuable given that the SIPMAJ reform provided a historical counterfactual against which to test the potential impact of pdia. In a sense, the real world experiment was simply whether a problem driven iterative engagement could help re-write the story of traditional project process failure evident in the SIPMAJ story. This kind of experiment is not open to control or randomization, however. As with all action research it is fraught with methodological complications that are likely to be overwhelming to those whose work resides in an overly positivist paradigm.

Action research methods are a product of the interpretive paradigm in social science, which emphasizes the use of qualitative information to interpret events and experiences. This does not mean that the research lacks structure or that the research product should be easily criticized because of undisciplined information capture or analysis. In an effort to maximize the validity of findings from the engagement, attention was paid to the particular research questions it addressed and the methods of collecting and assessing information and lessons associated with these questions:

- Four key questions were considered important in structuring the engagement. The first related to the viability of pdia as a reform process and was simply stated as, "Did the experience suggest that this kind of process is possible in a complex reform context like Mozambique's judicial sector?" The other three questions reflect the hypotheses stated earlier: "Did the reform group identity and respond to contextual factors that are commonly unseen in reform designs and undermine reform success?" "Did the reform group develop new capabilities that one could see leading towards an ultimate functional solution that fits contextual realities?" "Did the reform group maintain and expand its authority to do reform, allowing more authorized steps as the process moved on?"

- The main form of qualitative 'data' was provided through monthly reports from the local coaches to the international academic facilitator. These were supplemented by more regular informal contact between these parties and notes taken by all three external facilitators acting as participant observers in the main group meetings (which served similar purpose to the 'search conferences' referred to in work like Emery and Trist (1965) and Trist (1979)). This information was carefully assessed to find and explain evidence directly pertaining to the questions asked above. Particular attention was paid to evidence that showed pdia was or was not working, for instance, and to evidence that contextual constraints to reform were being identified and overcome. 


\section{Conclusion and the next chapter of this story}

The action research project has been underway for eight months now, and is producing significant evidence of how a problem driven iterative intervention can play out in a complex, hierarchical setting. It is still too early to form an entire narrative but the experience to date suggests that pdia does allow some retelling of the justice sector's data management reform story. This is very much a step by step (or poco-a-poco) story, with some emerging themes:

- The pdia-type process is certainly possible in a complex reform context like Mozambique's judicial sector, but it faces constant challenges. It is difficult, for instance, to ensure that those engaged in the reform are balancing their other work demands and creating time for the group meetings and change activities. It is also difficult to ensure that group members are receiving support from their authorizers. It is also challenging to ensure that all group members understand what the initiative is about and feel empowered to engage without going through bureaucratic supervisors.

- The iterative process is certainly helping the reform group to identity and respond to contextual factors that are commonly unseen in reform designs and undermine reform success. While initial action steps have been modest, the group has already been able to pinpoint missing capacities that were not previously diagnosed (in fundamental areas like using basic software packages for data analysis). The group has been able to initiate processes to close these capacity gaps (which had not been identified or closed in prior projects). Inter-agency tensions in the justice sector that ostensibly undermined the SIPMAJ operation have also become more apparent and identifiable, and have in some cases these tensions have also been addressed.

- The reform group has been able to develop new capabilities that one could see leading towards an ultimate functional solution that fits contextual realities. While the project is only in its eighth month and there have been periods of inactivity, the group has already assembled a larger set of data-in one place-than previously existed in the sector. The data is now combined in an excel spreadsheet which is accessible to members from statistical bureaus across the sector. Furthermore, the group has identified where its major data gaps are and is in the progress of thinking up next steps to close these gaps. It is also planning a training program under the project's auspices, focused on learning about building an ACCESS database (which the group has identified as one of its forthcoming action steps). The progress made to date has yielded more potential functionality than was achieved through five years and \$5 million dollars in the SIPMAJ project. The progress is also greater than the justice sector would have made if it were still doing this work through the World Bank's project, which is still under negotiation.

- Finally, the reform group has been able to maintain and expand its authority to do reform, allowing more authorized steps as the process moved on. This has not been a simple story, however, as there have been many challenges associated with the level of authority given to the group and to individuals in the group. These challenges have reinforced the importance of doing reform step-by-step and constantly paying attention to legitimacy and authority issues, at high levels of political leadership and at middle levels of bureaucratic management. The project went through at least two periods of slow engagement largely because of authorization problems, but 
these were addressed (to some degree at least) and there is evidence that the group is enjoying more authority as its work progresses. Increased amounts of data sharing between competing organizations in the justice sector suggests that the process enjoys more legitimacy than it did six months ago, for instance, as does a recent decision to use government money to fund statistical training for the reform group.

The full narrative behind these brief descriptions will be available soon, after the eight month project is completed. This will be structured in a systematic manner, discussing observations as they emerged in the flow of the project. It will also draw themes together from observations (as one sees in studies like Comstock and Fox (1995), Lau and Hayward (1997) and Olivero, Bane, and Kopelman (1997)). These themes will speak directly to the major questions many observers still ask about the applicability of arguments made in the literature on escaping capability traps in development. In so doing, the work will shed light on how pdia-type reforms could work to foster successful reform in complex hierarchical developing country governments. It will also provide some more detailed evidence on whether these approaches really help foster reforms that better fit such complex contexts.

\section{References}

Andrews, M. (2013a). The Limits of Institutional Reform in Development. New York, NY: Cambridge University Press.

Andrews, M. (2013b). 'How do Governments Get Great?' HKS Working Paper Series RWP13020, April.

Andrews, M. (2013c). 'Explaining positive deviance in public sector reform in developing countries.' HKS Working Paper Series RWP13-031, September.

Andrews, M., J. McConnell, and A. Wescott (2010). Development as Leadership Led Change. Washington, DC: World Bank.

Andrews, M., L. Pritchett, and M. Woolcock (2013). 'Escaping Capability Traps Through Problem Driven Iterative Adaptation (PDIA)'. World Development, 51: 234-44.

Bond, R. and D. Hulme (1999). 'Process Approaches to Development: Theory and Sri Lankan Practice'. World Development, 27(8): 1339-58.

Chambers, R. (1997). Whose Reality Counts? Putting the First Last. London: IT Publications.

Deming, W.E. (1986). Out of the Crisis. MIT Center for Advanced Engineering Study.

Dorado, S. (2005). 'Institutional Entrepreneurship, Partaking, and Covening'. Organization Studies, 26(3), 385-414.

Dorairaj, S., J. Noble, and P. Malik. Exploring Distributed Agile Projects: A Grounded Theory Perspective.

Emery, F.E., and E.L. Trist. (1965). 'The Causal Texture of Organizational Environments.' Human Relations 18, 21-32.

European Commission. (2009) End of Term Review of Support to the Justice Sector. Maputo: European Commission. 
Garud, R. and P. Karnøe (2003). 'Bricolage versus Breakthrough: Distributed and Embedded Agency in Technology Entrepreneurship'. Research Policy, 32, 277-300.

Gilmore, T., J. Kratz, and R. Ramirez. (1986). 'Action Based Modes of Enquiry and the HostResearcher Relationship.' Consultation, 5(3): 160-176.

Greenwood, R. and R. Suddaby (2006). 'Institutional Entrepreneurship in Mature Fields: The Big Five Accounting Firms'. Academy of Management Journal, 49: 27-48.

Hirschman, A. (1967). Development Projects Observed. Washington, DC: Brookings.

Korten, D.C. (1980). 'Community Organization and Rural Development: A Learning Process Approach'. Public Administration Review (September/October).

Lindblom, C. (1959). 'The Science of 'Muddling Through'. Public Administration Review, 19: 79-88.

MacIsaac, D. (1995). An Introduction to Action Research. http://www.phy.nau.edu/ danmac/actionrsch.html.

Mussanhane, E. (2008). Ad hoc expert group meeting on reconstructing Mozambique's state. October 2008. Available at isat.dcaf.cch

Olivero, G., K.D. Bane, and R.E. Kopelman. (1997). 'Executive Coaching as a Transfer of Training Tool: Effects on Productivity in a Public Agency.' Public Personnel Management 26(4), 461-469.

Open Society Foundation (2006). Mozambique: Justice Sector and the Rule of Law. Johannesbug: The Open Society Foundation.

Pritchett, L., M. Woolcock, and M. Andrews (2013). 'Looking Like a State: Techniques of Persistent Failure in State Capability for Implementation'. The Journal of Development Studies, 49(1): 1-18.

Rondinelli, D.A. (1993). Development Projects as Policy Experiments: An Adaptive Approach to Development Administration. 2nd Edition. London: Methuen.

Shewhart, W.A. (1980). Economic Control of Quality of Manufactured Product. American Society for Quality.

Seo, M.G. and W.E.D. Creed (2002). 'Institutional Contradictions, Praxis and Institutional Change: A Dialectical Perspective'. Academy of Management Review, 27(2): 222-47.

Susman, G.I. (1983). Action Research: A Sociotechnical Systems Perspective. Ed. G.Morgan. London: Sage, 95-113.

Trist, E.L. (1979). 'Referent organizations and the development of inter-organizational domains.' Proceedings from the $39^{\text {th }}$ Annual Convention of the Academy of Management, 23-24.

UNDP. (2007) Support to the police of the Republic of Mozambique. Project outcome evaluation. Final Report. Maputo: UNDP.

Uphoff, N. (1985). 'Fitting Projects to People'. In M. Cernea (ed.), Putting People First: Sociological Variables in Rural Development. New York: Oxford University Press.

Uphoff, N., M.J. Esman, and A. Krishna (1998). Reasons for Success: Learning from Instructive Experiences in Rural Development. West Hartford, CT: Kumarian Press. 
Vis, B. and K. van Kersbergen (2007). 'Why and how do Political Actors Pursue Risky Reforms?'. Journal of Theoretical Politics, 19(2): 153-72. 